EPJ Web of Conferences 75, 04005 (2014)

DOI: $10.1051 /$ epjconf/ 20147504005

(C) Owned by the authors, published by EDP Sciences, 2014

\title{
The Rare Earth Magnet Industry and Rare Earth Price in China
}

\author{
Kaihong Ding ${ }^{\mathrm{a}}$ \\ Yantai Shougang Magnetic Materials Inc (YSM), 888 Yongda St., Fushan Dist., Yantai 265500, China
}

\begin{abstract}
In the past four years, the price of rare earth metal fluctuates sharply for many reasons. Currently, it has become more stable and more reasonable. This presentation is focused on the effect about the rare earth metal price. Some motor manufacturers have shifted from rare earth permanent magnet to ferrite magnet. Many motor manufacturers changed the design for the motor cooling system to make the motor function at a lower temperature. Thus the consumption of Dy can be markedly reduced. As for manufacturer of $\mathrm{NdFeB}$ magnet, we are also trying to optimize our process to reduce to dependence of HREE such as Dy and Tb. HS process have been introduced to solve the problem. With more and more people focusing and engaging on the REE industry, the price of REE will be more transparent without too many fluctuations. China is considering the problems of balancing the environment, energy sources, and labor sources. The application field about $\mathrm{NdFeB}$ such as wind turbine generator, $\mathrm{HEV} / \mathrm{EV}, \mathrm{FA} / \mathrm{OA}$ is flourishing.
\end{abstract}

\section{Introduction}

The price of rare earth metal fluctuate sharply in recent years, thus makes more and more people are worry about the abundance of rare earth element especially for heavy rare earth element. Some motor companies shift from $\mathrm{NdFeB}$ magnet to Ferrite magnet to reduce the risk. Others motor companies reduce the working temperature about motor by redesign the cooling system for motor. YSM have development a new diffusion process which can reduce the consume about HREE such as Dy or $\mathrm{Tb}$ notable. Considering about more and more rare earth mine company are extend their capacity all over the world, the rare earth metal price should be more transparent and more stable. After 30 year of rapid growing in economy, China are met some problem such as energy, environment and labor sources. $\mathrm{NdFeB}$ magnet and downstream product are quite important points to solve these problems it should be flourishing in future.

\section{Discussion}

In the past 36 months, the rare earth metal price fluctuate sharply in China. For example, in July 2010, the price for $\mathrm{NdPr}$ alloy was just $240.5 \mathrm{RMB} / \mathrm{kg}$. Only one year later, it increased to around $1600 \mathrm{RMB} / \mathrm{kg}$. The price of $\mathrm{PrNd}$ alloy has increased about $565 \%$ within one year. In July 2013, it dropped to $357.5 \mathrm{RBM} / \mathrm{kg}$ that is just $22.4 \%$ compare with top price. The price of DyFe alloy also fluctuated with similar tendency. Figure 1 and Figure 2 show the price tendency about NdPr alloy and DyFe alloy in the past 36 months.

Many people want to know the reasonable range about rare earth. We plot a graph to compare the metal price with abundance for different element at different time.

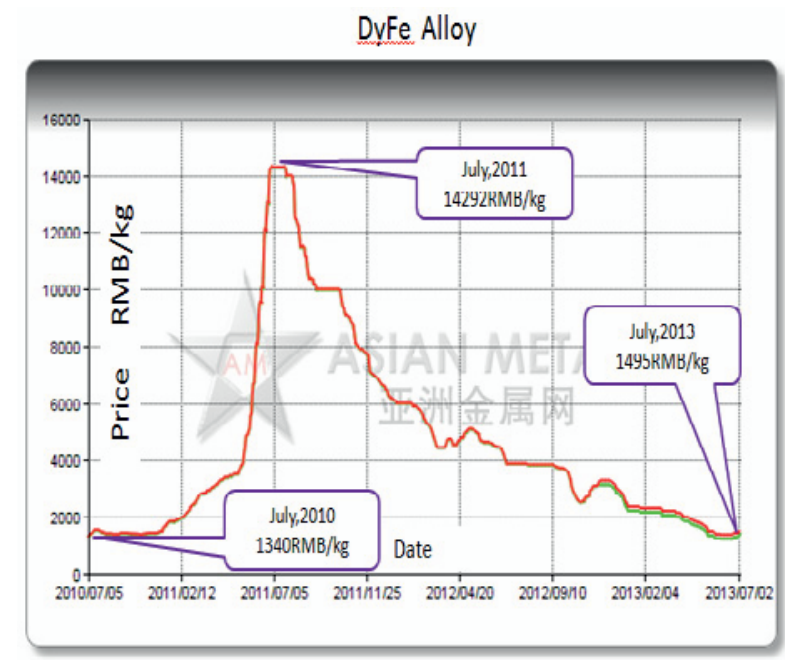

Figure 1. NdPr alloy price tendency in past 36 months [1]

${ }^{a}$ Corresponding author: khding@ysm.com.cn

This is an Open Access article distributed under the terms of the Creative Commons Attribution License 2.0, which permits unrestricted use, distribution, and reproduction in any medium, provided the original work is properly cited. 
Figure 3, Figure 4 and Figure 5 show the comparison result for 2011, 2012 and 2013. Base on the price of common metal which are widely used for industrial

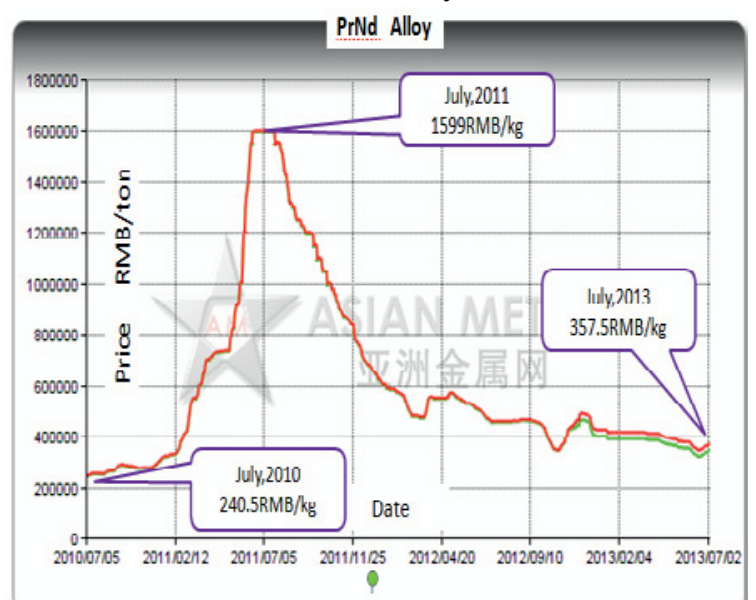

Figure 2. DyFe alloy price tendency in past 36 months [2]

application such as aluminum, iron, copper, molybdenum and silver we defined the reasonable range for rare earth metal.

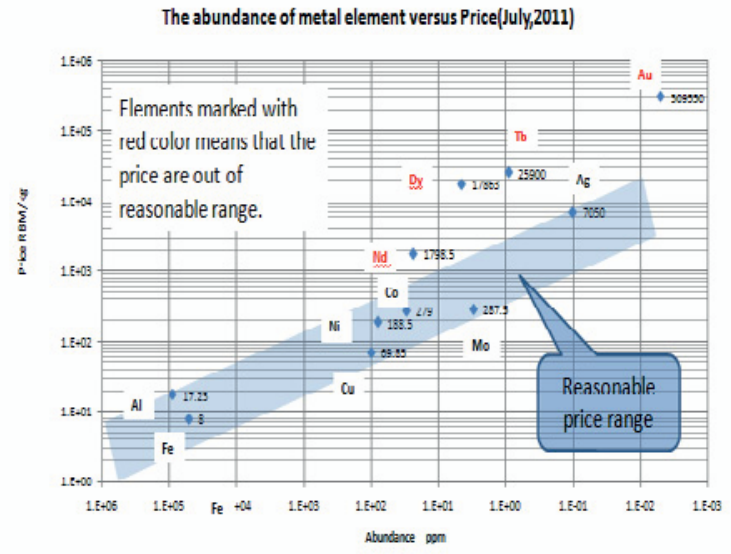

Figure 3. The abundance of metal element versus price in July, 2011.

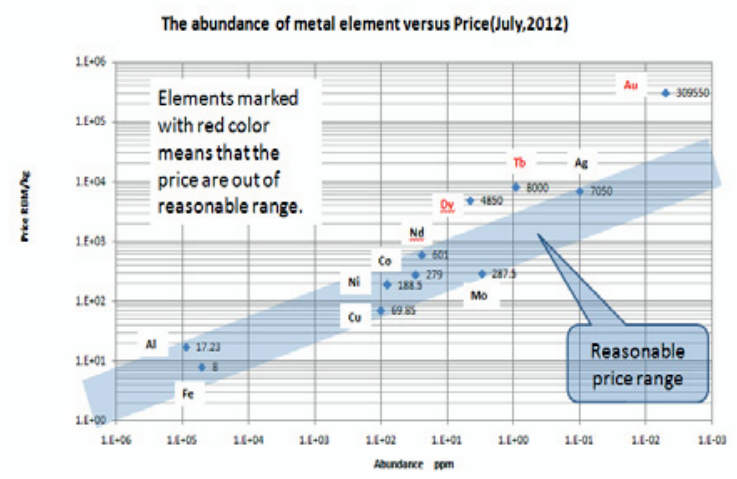

Figure 4. The abundance of metal element versus price in July, 2012.

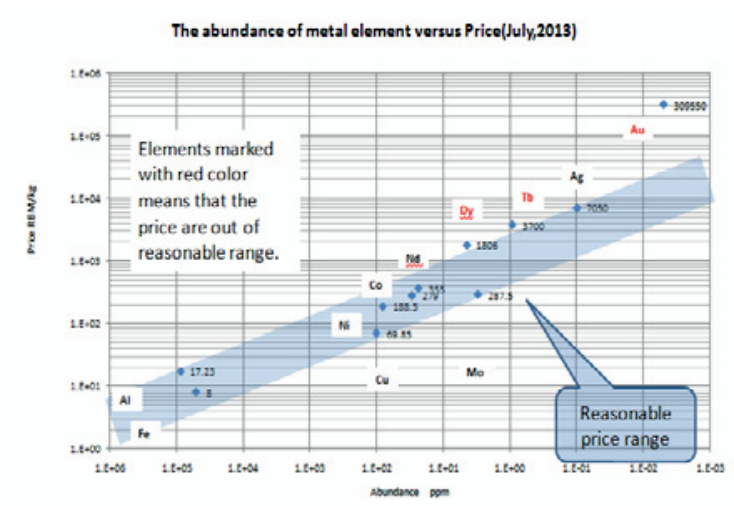

Figure 5. The abundance of metal element versus price in July, 2013.

In 2011, all rare earth metal price were too much higher compared with reasonable price range. Currently, the price for $\mathrm{NdPr}$ alloy has dropped into a reasonable price range, the price for DyFe alloy is still a little higher than reasonable price range.

Due to the fluctuation of rare earth price, some motor manufacturer are try to go back to use ferrite magnet. Although there is an increase of the weight of the motor, their worry is about rare earth resources. Figure 6 shows the different motors which will be used for automotive cooling fans.

Another company is trying to reduce the temperature of motor. For example the magnet for ESP motors can reduce the coercive force from $\mathrm{SH}$ grade to $\mathrm{H}$ grade. That will consume zero Dysprosium in the future.

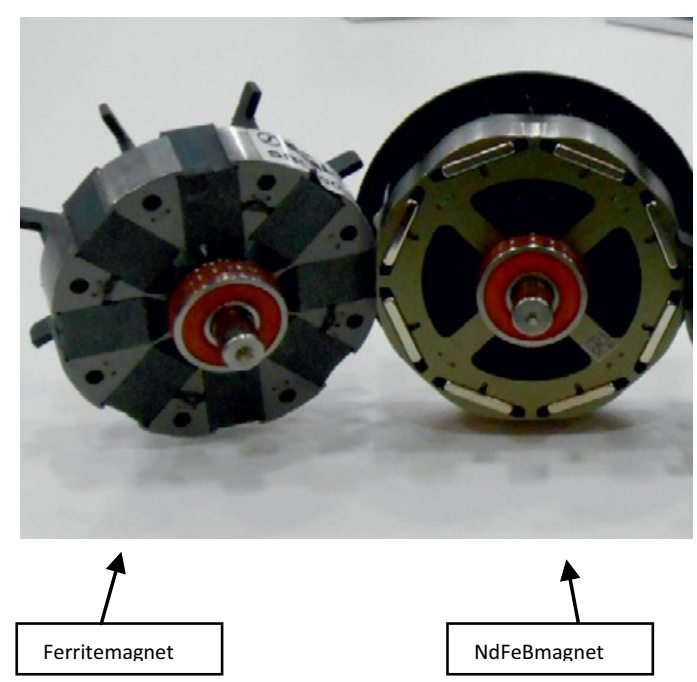

Figure 6. Automotive cooling fan motors which assembled by different type magnet. 


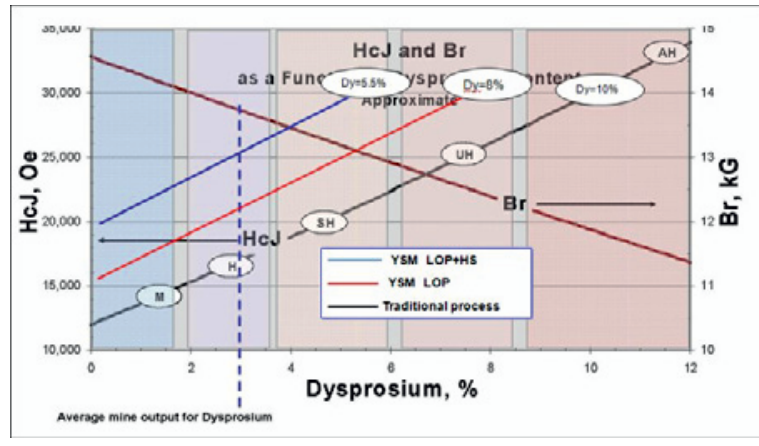

Figure 7. Dysprosium consume compare for different technical route

As for the manufacturer of sintered $\mathrm{NdFeB}$ magnet, YSM is engaged to reduce rare earth content for magnet by low oxygen process since the company was established in 2000.

The MPI (magnet performance index) can be over 74 . MPI is calculated by the following formula:

$$
M P I=\frac{\text { BHmax }}{7.96}+\frac{\mathrm{Hcj}}{79.6}
$$

the unit for BHmax should be $\mathrm{KJ} / \mathrm{m}^{3}$, and the unit for Hcj should be KA/m

Fig. 8 shows the latest development result by the HS process.

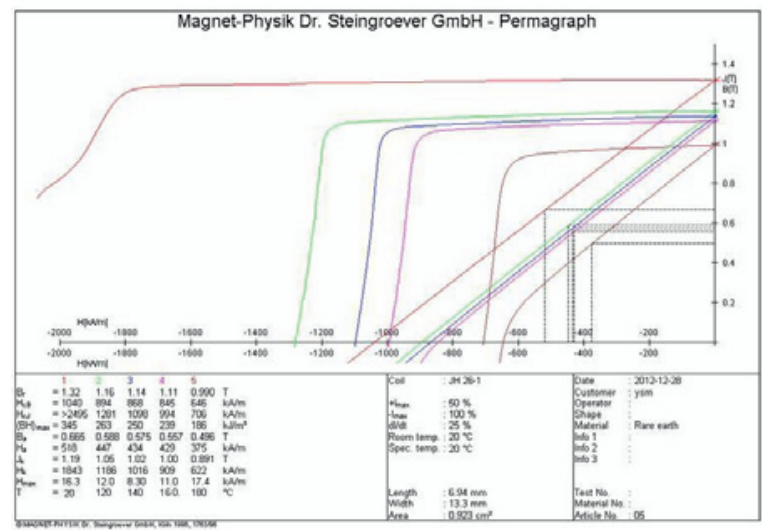

Figure 8. BH curves for N42EH magnet which made by HS process.

Due to the high price of Rare Earths in 2011, many companies outside of China begun to restart or build new plant to increase the supply of Rare Earths. Such companies are Molycorp, Lynas, Avalon, Arafura, etc.

We estimated that the Rare Earth supply will increase over $100 \%$ by the end of 2015 compare with the data of 2011.

During the past 30 years, China's economy has been growing at a unbelievable speed. The annual growth about GDP is around $10 \%$. Meanwhile, some problemshave appeared in recent years, such as petrol dependence, air pollution, aging of population. For the issue about petro dependence, China need more HEV and $\mathrm{EV}$ to save the gasoline. For the issue about air pollution, China not only need $\mathrm{EV}$ and $\mathrm{EV}$, but also need cleaner energy such as wind power and solar energy. As for issue about aging of population, China need more servo motor the realize factory automation and home automation. The solutions of all this problem are related to permanent magnet motor with $\mathrm{NdFeB}$ manget assembled inside

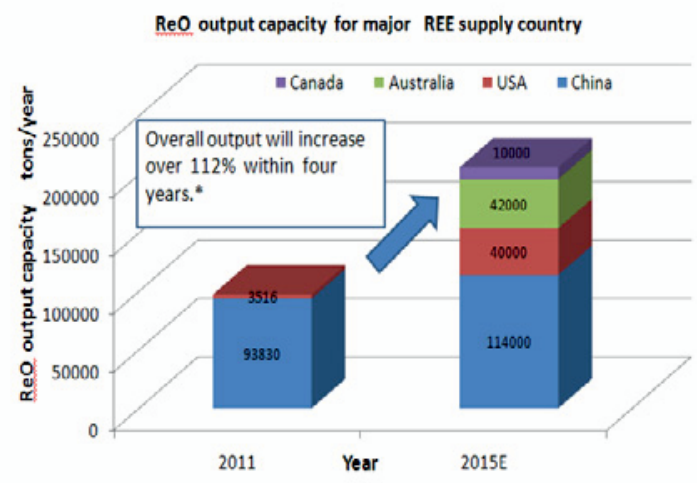

*: Some smaller REE mine were not included because we don't have the data. The actual data will be larger than what we estimated .

.

\section{Conclusion}

Currently, the Rare Earth prices are in reasonable price range quite close reasonable price range. With more and more companies being engaged in Rare Earth supply chain, the output will be doubled compared with the data of 2011 and the price will be more transparent, stable and reasonable.

China's economy growth style will be changed, Some problem should be overcome to make a long term growth, and sintered $\mathrm{NdFeB}$ magnets are important material to assist for this change. The application field about $\mathrm{NdFeB}$ will be flourishing.

\section{References}

1. http://www.asiametal.cn(accessed: July 4,2013)

2. http://www.asiametal.cn (accessed: July 4,2013)

3. http://www.asiametal.cn (accessed: July 4,2013)

4. Chinese Patent No.: ZL200910230609 